\title{
SEMEANDO SAÚDE - EDUCAÇÃO AMBIENTAL E ALIMENTAR EM ESCOLAS DE ITAQUI/RS
}

\author{
Lucas Santos da Silva \\ Universidade Federal do Pampa \\ lucastricolor9912@gmail.com \\ Paloma de Lourdes Ribeiro Carvalho \\ Universidade Federal do Pampa \\ palomarcarvalho@hotmail.com \\ Rafael Rodrigues de Souza \\ Universidade Federal de Santa Maria \\ rafael.r.de.s@gmail.com
}

Lauriane Romeiro de Almeida
Universidade Federal do Pampa
laurianealmeida97@hotmail.com

Filipe Godoy

Universidade Federal do Pampa filipegodoy93@gmail.com

Luciana Zago Ethur Universidade Federal do Pampa luethur@gmail.com

\section{Resumo}

O objetivo do trabalho foi apresentar e discutir os resultados de uma ação de extensão universitária desenvolvida com estudantes do ensino fundamental, em duas escolas do município de Itaqui/RS,buscando instrumentalizar e instigar, de forma lúdica, a importância da educação ambiental e alimentar como meios para melhoria da saúde, da qualidade de vida e para a formação cidadã. A ação foi desenvolvida com alunos do $4^{\circ}$ e $5^{\circ}$ ano do ensino fundamental (8 a 11 anos), dividida em duas etapas, a primeira focando na educação ambiental e a segunda na educação alimentar. Na primeira etapa foi aplicado um questionário e realizada uma roda de conversa juntamente com atividade prática de semeadura de alface em caixas de ovos contendo substrato para mudas, na segunda etapa foi proposta a construção de uma "horta ilustrativa", visando promover a educação alimentar. O questionário mostrou que $80 \%$ das famílias apresentam preocupação em reciclar embalagens, que algumas famílias cultivam certas verduras em suas residências e que os alunos possuem conhecimento sobre a importância das frutas e verduras para uma alimentação saudável, porém, apenas $50 \%$ as consomem diariamente. Com o auxílio da roda de conversa e atividade prática, os alunos semearam alface em caixas de ovos e levaram para suas residências. Com a organização da "horta ilustrativa" pode-se observar que as hortaliças mais conhecidas foram: tomate, cenoura, beterraba e alface. Portanto, a ação foi relevante para discentes/universidade e alunos/escolas, por tratar de educação ambiental e alimentar, além de formar vínculo entre as instituições de ensino.

Palavras-chave: Hortaliças. Sustentabilidade. Produção de Mudas. Educação Alimentar. Benefício dos Alimentos.

\section{SOWING HEALTH - ENVIRONMENTAL AND FOOD EDUCATION IN SCHOOLS OF ITAQUI/RS}

\begin{abstract}
The objective of the work was to present and discuss the results of a university extension action developed with elementary school students, in two schools in the city of Itaqui/RS, seeking to instrumentalize and instigate, in a playful way, the importance of environmental and food education as means for improving health, quality of life and citizen training. The action was developed with students from the 4th and 5th year of elementary school (8to 11 years old), divided into two stages, the first focus in gonenvironmental education and the second on food education. In the first stage, a questionnaire was applied and a conversation circle was carried out together with practical activity of sowing lettuce in egg cartons containing substrate for seedlings, in the second stage, the construction of an "illustrative garden" was proposed, aiming to promote food education. The questionnaire showed that $80 \%$ off a milies are concerned with recycling packaging, that some families grow certain vegetables in their homes and that students are aware of the importance off ruits and vegetables for healthy eating, but only $50 \%$ consume daily. With the help of the conversation wheel and practical activity, students sowed lettuce in egg cartons and took it to their homes. With the organization of the "illustrative garden" it can be seen that the most well-known vegetables were: tomatoes, carrots, beets and lettuce. Therefore, the action was relevant for students / university and students / schools, as it deals with environmental and food education, in addition to forming links between educational institutions.
\end{abstract}

Keywords: Vegetables. Sustainability. Seedling Production. Nutrition Education. Food Benefit. 


\section{SEMBRANDO SALUD - EDUCACIÓN AMBIENTAL Y ALIMENTARIA EN ESCUELAS DE ITAQUI/RS}

\section{Resumen}

El objetivo del trabajo fue presentar y discutir los resultados de una acción de extensión universitaria desarrollada con estudiantes de primaria, en dos escuelas de la ciudad de Itaqui/RS, buscando instrumentalizar e instigar, de manera lúdica, la importancia de la educación ambiental y alimentaria como medios para mejorar la salud, la calidad de vida y la formación ciudadana. La acción se desarrolló con estudiantes de 4to y 5to año de la escuela primaria (de 8 a 11 años), dividida en dos etapas, la primera enfocada en educación ambiental y la segunda en educación alimentaria. En la primera etapa, se aplicó un cuestionario y se realizó un círculo de conversación junto con la actividad práctica de sembrarlechugaen cartones de huevos que contienen sustrato para la splántulas, en la segunda etapa, se propuso la construcción de un "jardín ilustrativo", con el objetivo de promover la educación alimentaria. El cuestionario mostró que el $80 \%$ de las familias están preocupadas por el reciclaje de envases, que algunas familias cultivan ciertas verduras en sus hogares y que los estudiantes son conscientes de la importancia de las frutas y verduras para una alimentación saludable, pero solo el $50 \%$ consume diariamente. Con la ayuda de la rueda de conversación y la actividad práctica, los estudiantes sembraron le chuga en cartones de huevos y se la llevaron a sus hogares. Con la organización del "jardín ilustrativo" se puede ver que las verduras más conocidas fueron: tomates, zanahorias, remolachas y lechugas. Por lo tanto, la acción fue relevante para estudiantes / universidades y estudiantes / escuelas, ya que se ocupa de la educación ambiental y alimentaria, además de formar vínculos entre las instituciones educativas.

Palavras clave: Verduras. Sustentabilidad. Producción de Plántulas. Educación Alimentaria. Beneficio Alimentario. 


\section{INTRODUÇÃO}

No cenário contemporâneo, as questões de cunho nutricional e ambiental se encontram em crescente discussão, com tendência a menores impactos ambientais e consumo alimentar mais saudável. Alternativas para a inserção de determinadas práticas com visões sustentáveis podem ser aplicadas desde a infância, sendo esta fase de extrema importância no processo de aprendizagem.

A fase escolar representa um período de grande aprendizado na vida da criança, pois vários dos ensinamentos recebidos a acompanharão por toda a sua vida. Por isso, a educação alimentar antes dos dez anos de idade tem o potencial de reduzir a gravidade das doenças causadas pelos maus hábitos alimentares, sendo mais eficientes do que se adotadas na fase adulta (BERTINet al., 2010).Segundo Santos (2005), a educação alimentar é reconhecida como uma estratégia que visa à promoção e à proteção da saúde por meio da criação de hábitos e estilo de vida mais saudáveis, sendo considerada importante estratégia de ação dentro das políticas públicas, contribuindo de maneira expressiva na qualidade de vida da população.

Dentre os locais que se pode agir para promover a educação alimentar, tem-se o ambiente escolar, que é visto como espaço adequado para se desenvolver ações que incentivem a busca por qualidade de vida (RAMOS et al., 2013). Atividades desenvolvidas na escola estimulam um conhecimento gradativo, desde a infância até a fase adulta, sobre a importância da formação de hábitos alimentares saudáveis. As atividades educativas relacionadas à qualidade alimentar no processo de aprendizagem representam uma possibilidade concreta de impacto sobre a saúde e comportamento, instigando o desenvolvimento de habilidades para a vida de todos os membros da comunidade escolar (PEREZ \& ARANCETA, 2001). A intervenção positiva com foco na melhoria da educação alimentar abre a possibilidade de discussão sobre as questões ambientais, considerando a produção de alimentos de forma ambientalmente correta, possibilitando formar uma educação ambiental sólida já nas primeiras fases escolares.

No atual cenário educacional, chegamos numa etapa importante quando o assunto é meio ambiente, e isso se deve à excessiva exploração dos recursos naturais pela sociedade. O crescente aumento da civilização ocasionou em uma maior utilização dos recursos naturais, fazendo com que diversos problemas ambientais e sociais fossem surgindo, tornando a sustentabilidade um fator de extrema importância. A partir disso, nas últimas décadas, questões ambientais sustentam diversas discussões entre todos os setores da sociedade, surgindo, assim, a Educação Ambiental, tema o qual enfatiza a relação dos homens com o ambiente natural, as formas de preservá-lo e 
como administrar seus recursos adequadamente, de forma a mitigar os problemas relacionados à exploração excessiva (UNESCO, 2005).

A educação ambiental está em constante crescimento, tendo a função de atingir a população e também as novas gerações, por isso, torna-se uma necessidade contínua e permanente, devendo estar presente em todos os níveis e modalidades de ensino (LANA, 2015). A aplicação da educação ambiental no ambiente escolar possibilita o processo de aprendizagem e estimula a formação de cidadãos capacitados a viver sustentavelmente, melhorando a qualidade de vida da população, por meio da informação e conscientização (SEGURA, 2001). É necessária uma discussão sobre as questões e transformações de conhecimentos, valores e atitudes que devem ser seguidas diante da nova realidade a ser construída, constituindo uma importante dimensão que necessita ser incluída no processo educacional (KONDRAT; MACIEL, 2013), de maneira que não basta apenas a elaboração de ideias, sem realização da aplicabilidade das mesmas para solução de determinados problemas. Entre estas, está a reutilização de materiais alternativos (caixas de papelão, garrafas pet, embalagens vazias, latas de alumínio etc.), que podem ser utilizados em diversos campos do conhecimento, com o objetivo de gerar sustentabilidade no processo. A produção de mudas de hortaliças pode ser realizada em embalagens reutilizáveis, causando menor perturbação do ecossistema, e essa atividade da educação ambiental pode ser atrelada à educação alimentar, por tratar-se de hortaliças que devem fazer parte da alimentação saudável das crianças em idade escolar.

$\mathrm{Na}$ produção de mudas, principalmente das hortaliças, utilizam-se materiais de difícil decomposição no meio ambiente, a exemplo das bandejas de poliestireno expandido. Deste modo, a utilização de materiais alternativos torna-se uma estratégia que, além de possibilitar menor impacto ambiental, pode ser uma ferramenta para o ensino da reutilização de embalagens ao invés da opção de descarte. Dentre os materiais alternativos que permitem o cultivo de mudas de hortaliças, encontram-se caixas de produtos lácteos e de ovos, bem como a própria casca do ovo. Estes são exemplos de materiais que permitem reutilização e que apresentam rápida decomposição no ambiente, oportunizando produções sustentáveis.Segundo Oliveiraet al. (2017), o processo de aprendizagem de forma lúdica, provavelmente favorece o desenvolvimento da linguagem, do pensamento, da socialização, da iniciativa e da autoestima. Com base nisso, somase o conhecimento da produção de mudas com materiais alternativos aos aprendizados da importância dos vegetais na alimentação, para a faixa etária correspondente.

A produção com foco na sustentabilidade torna-se conectada a hábitos alimentares saudáveis e compreende-se que a formação destes hábitos é influenciada por fatores fisiológicos, psicológicos, socioculturais e econômicos e que tem sua formação iniciada na infância 
(DEMINICE et al., 2007; PACHECO, 2008). Segundo Boog (2010), a escola é um espaço destacado para desenvolver ações de educação alimentar. E, pode-se considerar como um local de sociabilidade do saber humano, onde ele pode ser construído, transformado e transmitido com e na ação humana (AZEVEDO; FERNANDES, 2010). Uma das formas de propagar as ações elencadas se caracteriza pela extensão universitária, cuja aplicabilidade no setor escolar permite a formação de um elo universidade-escola, que se torna crucial para a evolução profissional dos acadêmicos, sendo este um momento que oportuniza a colocação em prática do aprendizado obtido durante a graduação (RODRIGUES et al., 2013), bem como funciona como um recurso pedagógico capaz de estimular os mesmos para realização de exercícios nas diferentes áreas do conhecimento, conscientizando as crianças envolvidas no processo para boas práticas voltadas ao meio ambiente, alimentação saudável e formação social.

Diante do exposto, o presente relato tem como principal objetivo apresentar e discutir os resultados de um trabalho de extensão universitária desenvolvido junto a estudantes do Ensino Fundamental I, de duas escolas do município de Itaqui, Rio Grande do Sul, cuja finalidade foi instrumentalizar e instigar, de forma lúdica, a importância da educação ambiental e da adoção de alimentação saudável como meios para melhoria da saúde, da qualidade de vida e para a formação cidadã.

\section{MATERIAL E MÉTODOS}

A atividade de extensão foi realizada com alunos do ensino fundamental, objetivando despertar interesse para assuntos relacionados ao meio ambiente e à alimentação saudável, e também promover uma melhor interação entre os alunos, educadores e discentes da UNIPAMPA.

A ação foi desenvolvida por discentes do Curso de Agronomia, integrantes do Programa de Educação Tutorial (PET), e discentes do Curso de Nutrição, do Campus Itaqui da UNIPAMPA. As atividades foram realizadas em duas escolas estaduais do município de Itaqui RS (Escola A e Escola B), com alunos do $4^{\circ}$ e $5^{\circ}$ ano do Ensino Fundamental, com idades entre 8 e 11 anos. As ações foram divididas em duas etapas/datas, sendo o primeiro dia com foco na educação ambiental e o segundo, na educação alimentar. As atividades citadas ocorreram nos dias 23 e 24 de abril de 2018 na Escola A e nos dias 20 e 21 de outubro de 2018 na Escola B.

A proposição desta ação extensionista surgiu a partir de reuniões realizadas pelo grupo PET Agronomia, com participação de discentes do Curso de Nutrição, no início do ano de 2018, no qual buscavam-se alternativas para inserção de discussões sobre hábitos alimentares e 
ambientais adequados, nas etapas iniciais da educação básica estadual do município de Itaqui RS. A partir de considerações obtidas em reuniões, o planejamento foi construído e as escolas contatadas para organização do cronograma das atividades.

$\mathrm{Na}$ primeira etapa das atividades, os discentes do curso de Agronomia foram divididos em duas equipes, para que a ação fosse realizada nas duas turmas propostas $\left(4^{\circ}\right.$ e $5^{\circ}$ ano do ensino fundamental). Para iniciar a interação com os alunos, foi aplicado um questionário/formulário composto de nove questões, para avaliar o nível de conhecimento, e observar o interesse dos mesmos aos assuntos que seriam abordados (Figura 1 e Quadro 1).O questionário foi baseado em um levantamento inicial de periódicos da rede Scientific Electronic Library Online (SciELO) relacionados a atividade de extensão, priorizando vocabulário simples sobre os assuntos abrangidos, para facilitar o entendimento dos alunos.

Figura 1: Apresentação do grupo, da atividade e do questionário aplicado em sala de aula.

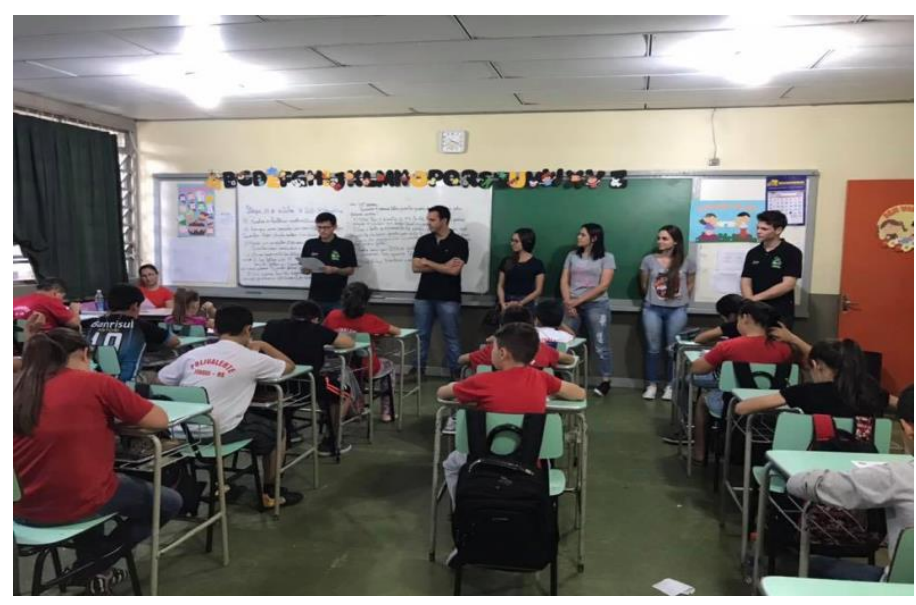

Fonte: Os autores, 2019.

Quadro 1: Questionário utilizado na avaliação do conhecimento dos alunos referente aos assuntos de educação ambiental abordados na atividade de extensão, desenvolvida nas escolas de ensino fundamental de Itaqui-RS.

1) $\mathrm{Na}$ sua casa, as embalagens vazias: caixinhas de leite, garrafas pet, caixinhas de ovo e potinhos (entre outros), são jogadas no lixo ou são lavadas e utilizadas para outras finalidades?

( ) Jogados no lixo. ( ) Lavados para serem usados.

2) Você acha que usando essas embalagens novamente está ajudando o meio ambiente?

( ) Sim. ( ) Não.

3) Você se preocupa com o meio ambiente? Gostaria de aprender uma forma legal de contribuir?

( ) Sim, eu me preocupo e quero aprender.

( ) Não me preocupo, e não tenho interesse em aprender. 
4) Você sabe o que é uma hortaliça?

( ) Sim. ( ) Não.

5) $\mathrm{Na}$ sua alimentação, você costuma comer diariamente algum desses alimentos: alface, couve, tomate, brócolis, repolho (entre outros)?

( ) Sim, praticamente todos os dias. （ ） Sim, eu como. Mas é raramente.

( ) Não, eu não gosto. （ ） Não, meus pais não compram.

6) Na sua casa, seus pais plantam algum desses alimentos citados acima?

( ) Sim, nós temos uma horta em casa. ( ) Não, porque não temos espaço.

O Não plantamos nenhum desses alimentos, mas temos outras plantas (flores, árvores frutíferas, etc).

7) O consumo desses alimentos é importante?

( ) Sim, eles possuem nutrientes importantes e benéficos para nós.

( ) Não, eles não fazem falta.

8) Você acha que é possível fazer mudas dessas plantas utilizando as embalagens vazias (caixinhas,...) que normalmente são jogadas fora?

( ) Sim, é possível. ( ) Não é possível, são muito pequenas.

( ) Não sei o que é uma muda.

9) Você sabe quais são os cuidados necessários para fazer uma muda?

( ) É só colocar a semente no solo (na terra) e molhar.

( ) Não sei o que é uma muda e nem como fazer uma.

( ) Não sei quais são os cuidados necessários, mas sei que não é só molhar.

Fonte: Os autores, 2019.

Posteriormente ao questionário, os alunos juntamente com os discentes da Agronomia, deslocaram-se para o pátio da escola para a realização de uma roda de conversa sobre os temas propostos (Figura 2 A) e a produção de mudas de hortaliças. Optou-se pelo uso da roda de conversa como estratégia metodológica, pela mesma permitir dinamismo na troca de informações entre locutor e ouvinte, a fim de facilitar a compreensão e estimular a curiosidade sobre os temas apresentados, abrindo espaços para questionamentos.Durante o diálogo, diversos conceitos foram apresentados aos alunos, tais como: o que as plantas necessitam para germinar e crescer; a produção de mudas de hortaliças pelos produtores e agricultores familiares; a utilização de materiais recicláveis/alternativos para produção de mudas; escolha das sementes; substratos mais 
Semeando saúde - educação ambiental e alimentar em escolas de Itaqui/RS

comuns no cultivo; profundidade de semeadura; cuidados necessários; quando e como transplantar as mudas; além de diversas curiosidades que foram surgindo ao longo da atividade.

Cada aluno teve a oportunidade de mexer no substrato comercial para mudas com pazinhas e com as mãos (Figura 2 B), preenchendo as células da caixa de ovos (de papelão) que posteriormente recebeu as sementes de alface (não tratadas com agrotóxicos) de duas variedades (lisa e crespa) para realizar a semeadura. Além disso, foram apresentados mais 10 tipos de sementes de outras hortaliças, para que os alunos pudessem ver a diferença de tamanho, cor e textura das mesmas. Após ocorrer a semeadura, procedeu-se a irrigação e as caixas de ovos foram disponibilizadas para serem levadas para suas residências, onde os cuidados ensinados deveriam ser colocados em prática. Para salientar a importância dos cuidados, foram mostradas algumas mudas de alface produzidas pelos ministrantes da atividade, em caixas de ovos, permitindo a eles verem como ficarão as mudas das sementes utilizadas.

Figura 2 A: Diálogo desenvolvido com a turma no pátio da escola. Figura 2 B: Produção de mudas.

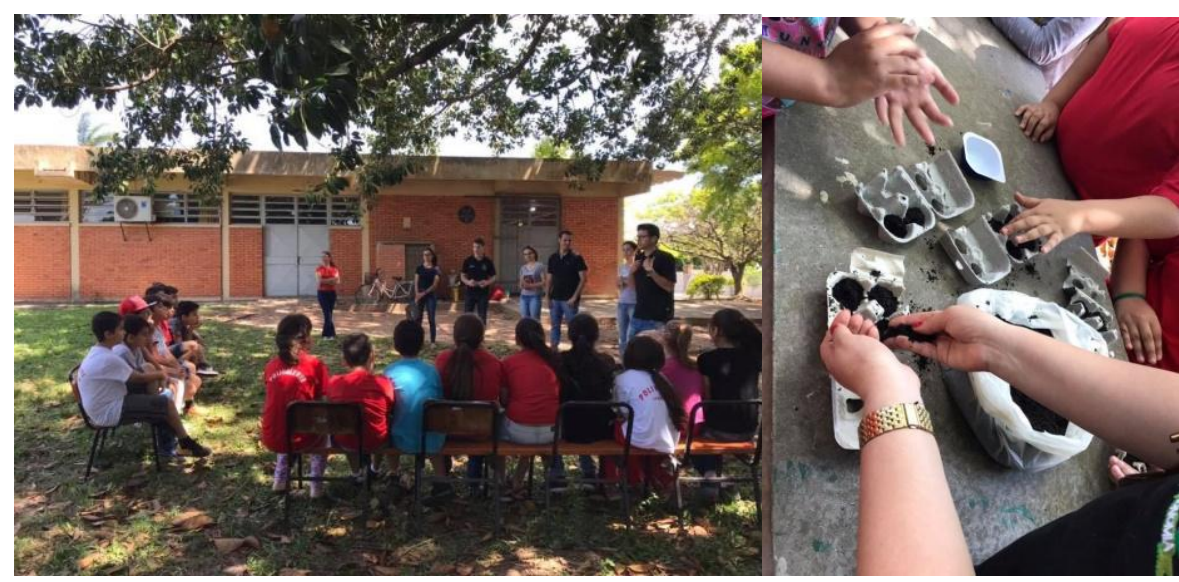

Fonte: Os autores, 2019.

Fonte: Os autores, 2019.

No segundo dia, a ação teve como finalidade despertar o interesse dos alunos em relação a conceitos de educação alimentar, de forma a estimular a alimentação saudável nas crianças. No intuito de dinamizar a atividade, foi proposto aos alunos a criação de uma "horta fictícia" em caixinhas de ovos de papelão, já que eles realizaram na etapa anterior a semeadura de hortaliças nas caixas. A mesma consistiu em fixar (plantar) diversos palitos contendo fotos de 22 hortaliças que são comercializadas nos mercados locais do município de Itaqui, entre elas: alface, brócolis, couve, cenoura, rúcula e beterraba.

Os alunos deveriam reconhecer a hortaliça, apresentando possíveis benefícios que a mesma poderia proporcionar quando consumida. A atividade foi realizada de forma descontraída, para estimular o interesse das crianças. Após o reconhecimento e debate sobre os benefícios, as 
Semeando saúde - educação ambiental e alimentar em escolas de Itaqui/RS

discentes do curso de Nutrição enfatizaram a importância do consumo das mesmas. A ordem, para colocar as placas na horta,organizando o "plantio" dos alimentos, foi a seguinte: $1^{\circ}$ ) A placa com a imagem ilustrativa do alimento, seguida da pergunta:"Vocês conhecem esse alimento?"; $2^{\circ}$ ) A placa com o nome do alimento, seguido da pergunta: "Para que serve esse alimento? Qual é o seu benefício?"; e $3^{\circ}$ ) A placa com o principal benefício do alimento (Figuras 3 A, 3 B e 4).

Figura 3 A: Organização das placas.

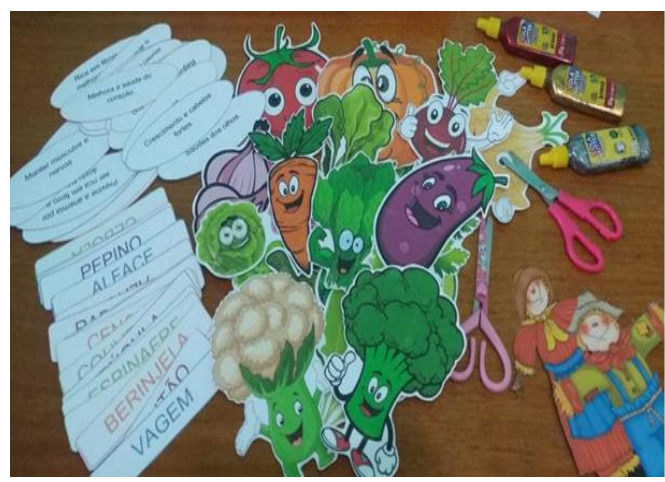

Fonte: Os autores, 2019.
Figura 3 B: Organização das caixas de ovos e substrato.

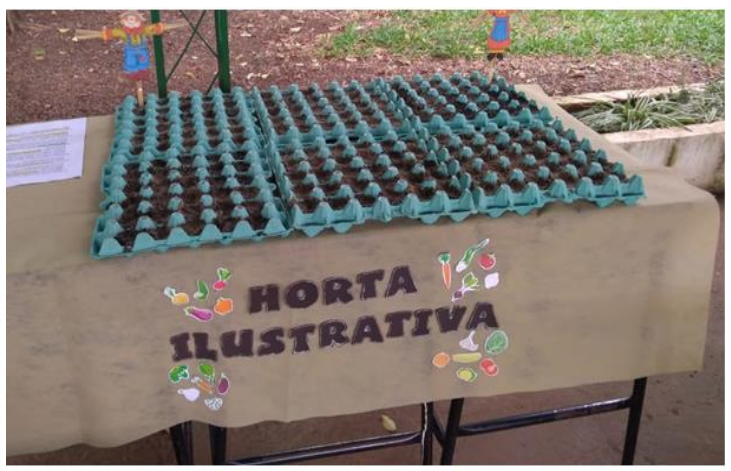

Fonte: Os autores, 2019.

Figura 4:Conversa com os alunos para a confecção da horta.

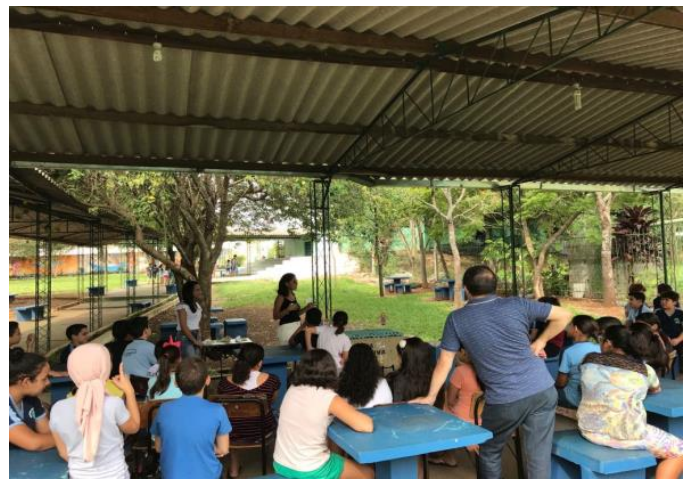

Fonte: Os autores, 2019.

\section{RESULTADOS E ANÁLISES}

As atividades relacionadas à parte de produção de mudas utilizando materiais recicláveis, principalmente embalagens vazias de ovos, foi analisada em um primeiro momento de acordo com o conhecimento intrínseco das crianças (questionário/formulário) e, posteriormente, de acordo com o conhecimento adquirido na roda de conversa e atividade prática (análise oral).

Ao término das atividades em ambas as escolas, realizou-se a análise das respostas obtidas nos formulários referentes ao conhecimento anterior à ação de extensão sobre os temas propostos neste trabalho, a fim de determinar a porcentagem representativa de respostas para 
Semeando saúde - educação ambiental e alimentar em escolas de Itaqui/RS

cada uma das questões. Os resultados encontrados para as Escolas A e B estão descritos na Tabela 1.

Tabela 1: Conhecimento dos alunos dos $4^{\circ}$ e $5^{\circ}$ anos de duas Escolas Estaduais de Ensino Fundamental de Itaqui - RS, sobre o desenvolvimento das plantas e educação ambiental.

\section{Questões}

Respostas
Escola A

(\%)

20

1. Na sua casa, as embalagens vazias: são jogadas no lixo ou são lavadas e utilizadas para outras finalidades?

a - Jogados no lixo

b - Lavados para serem usados $\mathrm{c}-$ Ambos

53

70

29

10

2. Você acha que a reutilização dessas

$\mathrm{a}-\operatorname{Sim}$

97

98

embalagens contribui com o meio

b - Não

3

2

ambiente?

3. Você se preocupa com o meio

a - Sim, eu me preocupo e quero

100

100 ambiente? Gostaria de aprender uma forma legal de contribuir? aprender.

b - Não me preocupo, e não tenho

0

0 interesse em aprender.

$$
\begin{aligned}
& a-\operatorname{Sim} \\
& b-N a ̃ o
\end{aligned}
$$

5. Na sua alimentação, você costuma

a - Sim, praticamente todos os comer diariamente algum desses dias.

alimentos saudáveis?

raramente.

$$
\begin{aligned}
& \text { c - Não, eu não gosto. } \\
& \text { d - Não, meus pais não compram. }
\end{aligned}
$$


6. Na sua casa, seus pais plantam a - Sim, nós temos uma horta em casa.

b - Não, porque não temos espaço.

c - Não plantamos nenhum desses alimentos, mas temos outras plantas (flores, árvores frutíferas, etc).

7. O consumo desses alimentos é a - Sim, eles possuem nutrientes importante? importantes e benéficos para nós. nem como fazer uma. necessários, mas sei que não é só molhar.

Fonte: Os autores, 2019.

Os resultados percentuais da primeira questão (Tabela 1), relacionada ao tratamento das embalagens com potencial de reutilização no âmbito doméstico, demonstram que as famílias, de forma geral, tem a noção e a preocupação com o reaproveitamento de materiais alternativos, porém, é possível melhorar este índice, em razão de que 18\% e 20\% desses materiais têm como destino o lixo, para as Escolas A e B, respectivamente. As respostas relacionadas às questões dois e três deixam claro que as crianças entendem a importância da preservação ambiental, desejando adotar métodos a fim de contribuir com estas ações. Entretanto, Sato (2001) explica que apenas a 
consciência não é suficiente para a educação ambiental, é necessário a realização de práticas que ajudem a solucionar os problemas do mundo, papel que pode ser desempenhado pela extensão universitária.

As questões de quatro a sete (Tabela 1) tratam sobre as hortaliças, desde o conceito até o consumo das mesmas pelas crianças. A palavra hortaliça pode não ter sido a melhor escolha para ser utilizada no questionário, em vista que, em média, 57,5\% dos alunos responderam não saber do que se tratava, talvez as denominações comuns: legumes e verduras tivessem êxito no conhecimento geral. Em média, 95,5\% dos alunos sabem que as hortaliças são importantes (questão 7), porém, somente cerca da metade dos mesmos consomem diariamente em sua alimentação (questão 5). Estes dados corroboram com estudos de Mioto e Oliveira (2006) afirmando que alimentos reguladores e saudáveis, como hortaliças e frutas, refletem em uma baixa preferência pelas crianças, contudo, mesmo que em porcentagens reduzidas, ainda estão presentes na alimentação. Parcela deste resultado do baixo consumo de alimentos saudáveis está atrelado à mídia, com propagandas tendenciosas de alimentos impróprios ao consumo em demasia, principalmente na faixa etária escolar (MIOTO \& OLIVEIRA, 2006).

Itaqui é uma cidade considerada de pequeno porte, apresentando economia voltada principalmente para a agropecuária, podendo ser a explicação para que entre 30 e 45\% das famílias cultivem algum tipo de hortaliça em suas residências. Porém, mesmo havendo essa experiência em seus lares, a maioria dos alunos respondeu que não conhece ou não sabe produzir mudas "É só colocar a semente no solo (na terra) e molhar" (questão 9), outra justificativa é a opção de aquisição de mudas devidamente prontas para o transplante em lojas agropecuárias. Este dado reflete uma deficiência de conhecimento sobre os requerimentos básicos e necessários para o pleno desenvolvimento e crescimento de plantas.

Diversas dúvidas e questionamentos surgiram ao longo do diálogo com as crianças, algumas simples de serem respondidas, outras, por outro lado, bem elaboradas e complexas que foram esclarecidas de forma científica/acadêmica. Tais questões salientam o interesse dos alunos em relação à temática da produção de mudas e como proceder corretamente na atividade. Para ilustrar a roda de conversa, foram elencados alguns dizeres e questionamentos dos alunos (Quadro 2).

Quadro 2: Dizeres e questionamentosdos alunos durante a roda de conversa. 


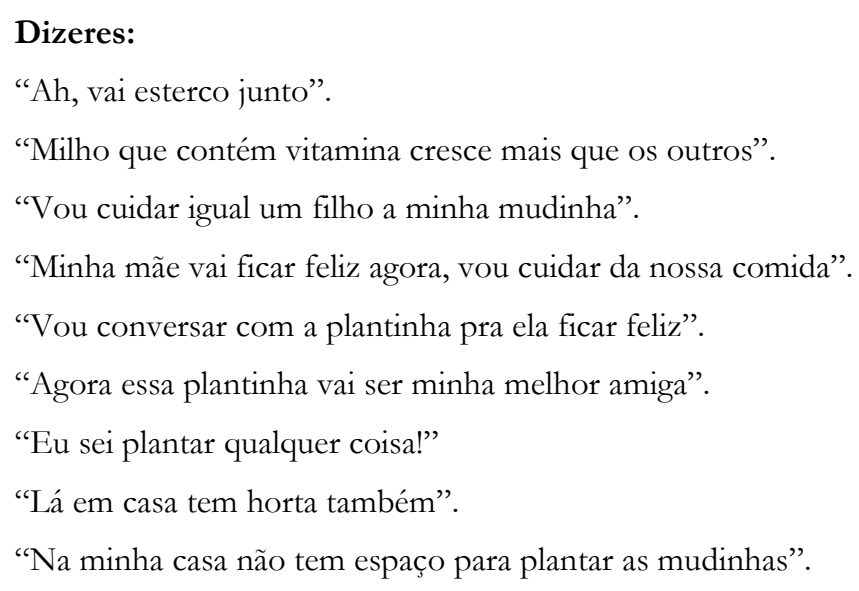

\section{Questionamentos:}

“Todas as plantas são produzidas por semente?"

"Quanto tempo precisa colocar água?"

"Para que serve o adubo?"

"Por que usar esterco no substrato?"

"O que fazer depois que as plantas estiverem crescidas?”

"Por que a semente é um ser vivo?"

"Quanto tempo demora pra muda nascer?"

"Por que demora tanto tempo assim?"

"Por que algumas sementes são coloridas?"

"Posso usar qualquer coisa da planta para produzir uma muda?"

Fonte: Os autores, 2019.

Esses dizeres e questionamentos (Quadro 2) demonstram o interesse das crianças durante o desenvolvimento da atividade. Os questionamentos realizados pelos alunos eram redirecionados para sua turma, com a intenção de haver alguém com conhecimentos obre o assunto para responder ao colega. Somente após essa etapa os ministrantes da atividade respondiam, usando as respostas dos alunos para compor a resposta final, estimulando a participação de todos. A roda de conversa foi descontraída e procurou-se incluir todos os alunos na discussão dos assuntos apresentados. Os dizeres encontrados no Quadro 2 vêm reforçar o que foi presenciado pelos ministrantes da atividade, no que diz respeito ao cuidado que os alunos tiveram com as caixas de ovos e suas reações: "Não corre", "Cuidado para não me bater", "Olha para o chão quando está caminhando", "Espero que chegue até em casa direitinho"...

Um fato que deve ser salientado foi o imediatismo e a falta de conhecimento com relação ao desenvolvimento das mudas/plantas. Um dos alunos da Escola A perguntou: "Quanto tempo vai levar para a semente formar uma muda como essa que vocês trouxeram?" A resposta foi: "Vai 
levar perto de dez dias". O menino: “O quê? Tudo isso?” E alguns colegas dele ficaram olhando de forma curiosa para a caixa de ovos onde as sementes foram semeadas para ver se isso realmente era verdade, se as plantinhas já não estariam surgindo do substrato. Isso confirma as respostas encontradas para a questão número 9 (Tabela 1): "Você sabe quais são os cuidados necessários para fazer uma muda?", as respostas para "sim" continham o complemento que "se deveria apenas colocar água". Assim, pode-se inferir que os alunos apenas haviam ouvido falar em mudas e colocar água, porém não tinham a real compreensão do que fosse produzir uma muda e do crescimento de uma planta.

Antes de iniciar a atividade do segundo dia, foi perguntado para as turmas: "Vocês estão cuidando das sementes que vocês semearam na caixa de ovos?" e surgiram várias respostas: "Sim", "Minha mãe está cuidando", "Minha irmã colocou pra fora de casa e o cachorro virou", "Deixei lá na horta junto com as outras plantas", "Está na minha sacada", "Eu não tinha lugar e aí dei para a vizinha"..., contudo, pode-se observar que eles sabiam onde a caixa de ovos estava e o que estava ocorrendo com as sementes, mostrando que a vivência da atividade anterior foi importante e gerou aprendizagem sobre o assunto tratado.

Então, deu-se continuidade à atividade anterior, realizada pelos discentes da Agronomia, para a parte da alimentação saudável, com as discentes do curso de Nutrição. Foi falado para os alunos: "Na atividade anterior vocês semearam as sementes nas caixas de ovos, e agora nós vamos fazer de conta que as plantas cresceram e vamos organizar uma horta!!”

A horta ilustrativa foi organizada com a participação ativa dos alunos. As placas eram fixadas em cada uma das células presente nas caixas de ovos, até o preenchimento completo da mesma, contemplando os 22 alimentos com 66 placas (Figura 6).

Figura 5: Horta ilustrativa concluída.

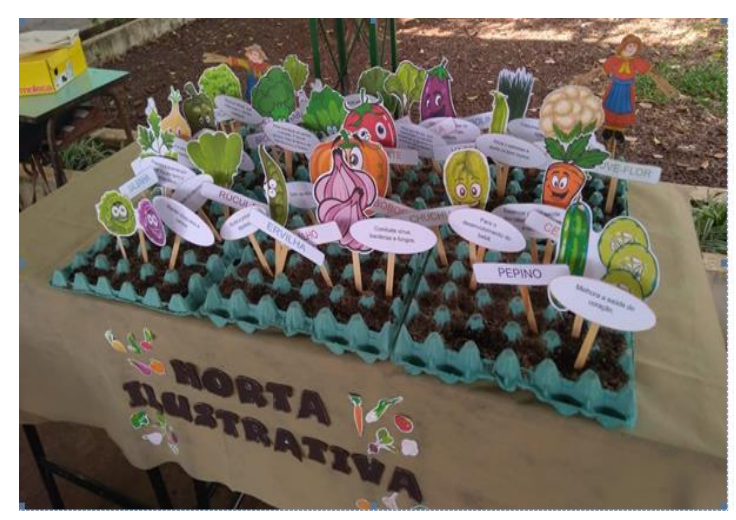

Fonte: Os autores, 2019. 
No decorrer da atividade era perceptível a euforia das crianças, envolvidas totalmente com os processos do trabalho, demonstrando participação ativa. A cada alimento plantado na horta ilustrativa era realizada a pergunta: "Quem gosta de (respectivo alimento)?", objetivando se ter uma ideia geral de quais eram os alimentos preferidos para consumo. Os produtos de maior consumo nas duas escolas, pelas duas turmas, foram: tomate, cenoura, beterraba e alface. Outros alimentos como: berinjela, pepino, rabanete, rúcula e agrião se apresentaram como os mais "rejeitados" pelas crianças, não fazendo parte de sua preferência para o consumo.

Pode-se observar que a ação despertou a curiosidade e interesse sobre a diversidade de hortaliças disponíveis ao consumo, muitas desconhecidas pela maioria dos alunos, como a berinjela, e que já exclamavam "não gosto" sem ao menos ter provado. Isso ficou evidente porque quando a resposta era "não gosto", logo era perguntado "Você já provou? De que forma comeu?", mostrando que a ideia de não gostar era por não conhecer e pelo aspecto do alimento não vir ao encontro conceitual que a criança tem de ser algo "bom". A intervenção de promoção de hábitos alimentares saudáveis deve ser ressaltada na infância para que esses hábitos permaneçam ao longo da vida. Este estilo de vida saudável precisa ser introduzido de forma gradual e mantido na idade escolar, e priorizando esses hábitos mediante estratégias de educação nutricional (BERTIN, et al., 2010).

Com relação à alimentação diária das crianças, foi possível observar que, em geral, elas conhecem os alimentos, porém, não os consomem em diversidade, caracterizando uma "monotonia alimentar", consumindo sempre os mesmos alimentos. Essa rejeição evidenciada por algumas das hortaliças é adquirida muitas vezes pela recusa de provar o alimento ou pelo desgosto do sabor e ou cor. Outro motivo que pode ser considerado é a localização da cidade de Itaqui, situada em uma região com a tradição do consumo de carne (inclusive como charque) e arroz, tradição de comida chamada "campeira", onde as famílias foram mudando a alimentação aos poucos e incluindo diversidade de vegetais. Porém, muitas ainda mantêm a tradição no dia a dia. Por isso a importância da atividade promovida em escolas, caracterizando uma das estratégias específicas da Política Nacional de Promoção de Saúde por meio do desenvolvimento de ações para a promoção da alimentação saudável no ambiente escolar (BRASIL, 2006).

A idade escolar corresponde à faixa etária entre sete e dez anos de idade, o período em que ocorrem as maiores exigências nutricionais. A fase escolar sintetiza a evolução desde a vida intrauterina, passando pela fase lactente/pré-escolar e até a própria idade escolar. Com base nisso, essa faixa etária se torna um ciclo propício para educação nutricional infanto-juvenil. As intervenções antes dos dez anos de idade reduzem a gravidade das doenças causadas pelos maus 
hábitos alimentares de forma mais eficiente do que as mesmas intervenções na fase adulta (BERTIN, et al., 2010).

No avanço da atividade eram realizados relatos, por parte das crianças, sobre quais eram os principais benefícios de alguns alimentos, mostrando que elas tinham conhecimento sobre alguns, assim como a importância do consumo dos mesmos. Enfatizaram, também, sobre a pigmentação dos vegetais e como se dava o seu crescimento, ensinamentos estes provenientes das aulas, de sua instituição e das atividades do primeiro dia, com os discentes do curso de Agronomia. Durante e ao final do trabalho, várias questões foram realizadas pelos alunos: "Por que a couve na panela diminui de tamanho?”; "Dá pra comer tudo que é verde?”; "Por que o rabanete é amargo?"; "Por que os vegetais são verdes?"; "Todo o alimento passa por fotossíntese?”; “A cenoura faz bem para os olhos?”; "O tomate é uma verdura ou um fruto?”; "Quantos desses alimentos eu preciso comer para ficar saudável?”; "Qual alimento é o que tem mais vitamina?"; "E se eu não gostar desses alimentos, preciso comer mesmo assim?”. Os alunos se sentiram à vontade para realizar perguntas, contar histórias familiares sobre comidas e comentar sobre diversidades de assuntos, como: "A abóbora é usada no dia das bruxas"; "Rabanete é tão ruim que não deve servir pra nada"; "Lá em casa tem alface, mas eu não como... é muito molenga".

As atividades lúdicas são indispensáveis para uma boa prática pedagógica, podendo contribuir e ser material de apoio para as aulas teóricas. São de fundamental importância e indispensáveis para o desenvolvimento e amadurecimento psicólogo, social e cultural de uma criança. É importante para o aluno fazer a interação do conteúdo e conseguir relacionar a teoria com prática, tornando o estudo mais atrativo e, consequentemente, maximizando os níveis de aprendizado e trazendo fixação dos conhecimentos.

\section{CONSIDERAÇÕES FINAIS}

As atividades permitiram aos alunos explicitar os seus conhecimentos e ao mesmo tempo mostrou a necessidade de contextualizá-los quanto à real importância da educação ambiental e alimentar para sua vida e para a comunidade.

A roda de conversa somada à atividade prática de produzir mudas permitiu aos alunos elaborar conceitos e construir o conhecimento sobre a utilização de materiais recicláveis e a vida das plantas, incorporando práticas e ideias de sustentabilidade para sua vida. 
Semeando saúde - educação ambiental e alimentar em escolas de Itaqui/RS

Como perspectivas futuras, pretende-se agregar à roda de conversa e atividade prática a entrega de folheto, com vocabulário simples, facilitando o entendimento sobre os temas abordados e permitindo a continuidade das ações além do âmbito escolar, abrangendo as famílias.

A organização da horta ilustrativa mostrou aos alunos a diversidade de alimentos que podem e devem ser consumidos para se ter alimentação saudável, contribuindo para que desde cedo tenham preocupação com a educação alimentar.

A ação foi relevante tanto para os discentes e a universidade, quanto para os alunos e as escolas, por tratar de questões ambientais e alimentares, além de formar vínculo entre as instituições de ensino. A universidade contribuiu com ensinamentos referentes aos temas propostos e os alunos deram feedback positivo, por meio de suas respostas, indagações e interesse demonstrado.

Espera-se que a ação tenha contribuído para a formação social das crianças e que as experiências vivenciadas sejam duradouras na fase adulta, tornando-os responsáveis em cuidar do meio ambiente e que tenham uma alimentação saudável.

\section{REFERÊNCIAS}

AZEVEDO, D.S.; FERNANDES, K.L.F. Educação Ambiental na Escola: um estudo sobre os saberes docentes. Educação em foco, v.14, n.2, p.95-119, 2010.

BERTIN, R. L.; MALKOWSKI, J.; ZUTTER, L. C.; ULBRICH, A. Z. Estado nutricional, hábitos alimentares e conhecimento de nutrição em escolares. Revista Paulista de Pediatria, v. 28 , n. 3, p. 303-308, 2010.

BOOG, M.C.F. Programa de educação nutricional em escola de ensino fundamental de zona rural. Revista de nutrição, v.23, n.6, p. 1005-1017, 2010.

BRASIL. Política Nacional de Promoção de Saúde. Ministério da Saúde. Brasília: Ministério da Saúde, 2006.

DEMINICE, R.; LAUS, M.F.; MARINS, T.M.; SILVEIRA, S.D.O.; DUTRA-DE-OLIVEIRA, J.E. Impacto de um programa de educação alimentar sobre práticas alimentares e estado nutricional de escolares. Alimentos e Nutrição, v.18, p.35-40, 2007.

KONDRAT, H.; MACIEL, M.D. Educação ambiental para a escola básica: contribuições para o desenvolvimento da cidadania e da sustentabilidade. Revista Brasileira de Educação, v.18, n.55, p.825-1058, 2013.

LANA, Z. M. O. O ensino regular e a educação ambiental formal: emergência, princípios, e elementos normativos. Revista Eletrônica em Gestão, Educação e Tecnologia Ambiental, v.29, n.2, p.1110-1123, 2015. 
Semeando saúde - educação ambiental e alimentar em escolas de Itaqui/RS

MIOTO, A. C.; OLIVEIRA, A. F. A influência da mídia nos hábitos alimentares de crianças de baixa renda do Projeto Nutrir. Revista Paulista de Pediatria, v. 24, p. 115-120, 2006.

PACHECO, S.S.M. O hábito alimentar enquanto um comportamento culturalmente produzido. In: FREITAS, M.C.S.; FONTES, G.A.V.; OLIVEIRA, N. Escritas e narrativas sobre alimentação e cultura. Salvador: Edufba; 2008. p. 217-38.

PEREZ, R.C.; ARANCETA, J. School-basednutritioneducation: lessonslearnedand new perspectives. Public Health Nutrition, v. 4, n. 1, p. 131-139, 2001.

OLIVEIRA, J.C.; COSTA, S.D.; ROCHA, S.M.B. Educação Nutricional com atividade lúdica para escolares da rede municipal de ensino de Curitiba. Cadernos da Escola e Saúde, Curitiba, v. 2, n. 6, p. 100-116, 2017.

RAMOS, P.F.; SANTOS, S.A.L.; REIS, C.B.A. Educação alimentar e nutricional em escolares: uma revisão de literatura. Cadernos de Saúde Pública, v.29, n.11, p.2147-2161, 2013.

RODRIGUES, A.L.L.; PRATA, M.S.; BATALHA, T.B.S.; COSTA, C.L.N.do A.; NETO, I.de F.P. Contribuições da extensão universitária na sociedade. Caderno de Graduação: Ciências Humanas e Sociais, v.1, n.16, p.141-148, 2013.

SANTOS, L.A.S. Educação alimentar e nutricional no contexto da promoção de práticas alimentares saudáveis. Revista de Nutrição, v.18, n.5, p.681-692, 2005.

SATO, M. Debatendo os desafios da educação ambiental. Revista Eletrônica do

Mestrado em Educação Ambiental, Rio Grande: Universidade Federal do Rio Grande;FURG, v. 1, p. 14-33, 2001.

SEGURA, D. S. B. Educação Ambiental na escola pública: da curiosidade ingênua à consciência crítica. São Paulo: Annablume: Fapesp, 2001. 214p.

UNESCO. Década da Educação das Nações Unidas para um Desenvolvimento Sustentável, 2005-2014: documento final do esquema internacional de implementação, Brasília, Brasil, 2005. 120 p.

Recebido em: 26/07/2019

Aceito em: 15/04/2020 